\title{
Managing the Challenges of Vocational Education and Training in Indonesia-The Mire of Uncertainty!
}

\author{
Abdullah Helmy $^{1 *} \quad$ Brian Fairman ${ }^{2} \quad$ Adam Voak $^{2}$ \\ 1.International Division, Malang State Polytechnic Jl. Soekarno Hatta No 9 \\ Lowokwaru, Malang, Indonesia \\ 2.Cairns Institute, James Cook University McGregor Rd. Cairns, Queensland 4878, Australia \\ *E-mail of the corresponding author: Abdullah.Helmy@polinema.ac.id
}

\begin{abstract}
The Indonesian Vocational Education and Training (VET) sector currently faces many challenges. Across the country, a complex historical amalgam of training facilities is overseen by a centralized administration, which itself is composed of many different Institutes and bureaucracies, each of which has some coordination and resource responsibilities for the implementation of VET. Managing this VET provision is an essential part of Indonesian's training reform agenda. The Indonesian Government's higher educational reform Merdeka Belajar Kampus Merdeka has recently been introduced to radically reshape the tertiary education sector through 'emancipated learning' requiring innovation, creativity and collaboration. This policy shift has challenged industry, civil society, and educationalists to steer a pathway toward tertiary educational reforms particularly in respect of the challenge in preparing human capability programs that meet the demands of a modern workforce. Therefore a refocus towards closer partnerships between VET providers and the industries they serve is urgently needed in order to meet the competency standards required of a modern Indonesian workforce. This paper explores these national and international challenges as they pertain to managing these transformational VET reforms.
\end{abstract}

Keywords: Vocational Education and Training, Competency standards, Kampus Merdeka.

DOI: $10.7176 / \mathrm{JEP} / 12-33-03$

Publication date: November $30^{\text {th }} 2021$

\section{Introduction}

The Indonesian Vocational Education and Training (VET) sector currently faces many challenges. Across the country, a complex historical amalgam of training facilities is overseen by a centralized administration, which itself is composed of many different Institutes and bureaucracies, each of which has some coordination and resource responsibilities for the implementation of VET. Currently, Indonesia has thirteen separate ministries that manage and operate the VET sector (Sayuti, 2016), and this environment of cross-ministry responsibility has created tensions and rivalry between ministries which appears to have led to 'Sectorial ego (ego sektoral)' (Sayuti, 2016). Managing this VET provision is an essential part of preparing human capability programs that meet the demands of a modern workforce. In the context of this multi-faceted amalgam of VET provision, the current Minister of Education and Culture, Nadiem Makarim, describes his government's reforms in higher education as emancipated learning Merdeka Belajar Kampus Merdeka (Emancipated Learning) 'there has never been a greater opportunity to breakdown the 'silos' between industry and the social sector, university faculties and the broader academic community’ (Neumann, 2021).

Implementing VET reforms is both necessary and challenging, and it would seem appropriate to call for a coordinated response which would require the establishment of a 'single' VET management authority. This request is formulated around an understanding that in the past 'a poorly formulated policy, inconsistencies in the policy, sectorial ego and inter-ministerial rivalry, fragmented authority and management of TVET' (Sayuti, 2016) have all contributed to a negative view of policy frameworks. The current approach of the Ministry of Educations' Merdeka Belajar Kampus Merdeka has sought to 'free the individual' from the constraints of 'standardization' and an educational policy of 'one size fits all philosophy' (Neumann, 2021). In light of these policy shifts, it would seem that to stimulate the reorganization of VET reforms, the development of a prescriptive Law may be needed to harmonize the current conflicts of interest among the ministries involved, and further, to ensure adequate resources are available for successful implementation.

The preceding observations point to the need for a healthy management initiative to stabilize the tertiary education and VET sector. This review paper explores the challenges of managing VET in Indonesia by examining: (i) policy initiatives; (ii) national coordination and human capability development; (iii) Industry-VET partnership engagement; and (iv) management implications for VET providers and business organisations. These perspectives are in the context, and consistent with, the mandated requirement of Verse 28 of Law No. 13, Year 2003, on Manpower, and Verse 10 of Government Regulation No. 31, Year 2006, on the National Vocational Training System. In such a situation, the role of management will need to attend to planning, organizing, coordinating, commanding and controlling an agreed strategy (McLean, 2011). 


\section{Planning: policy borrowings from abroad}

Indonesia, like many 'developing countries', are faced with decisions regarding what was required to happen within the country to: (i) provide opportunities for the community to develop skills to establish their future prosperity, (ii) to secure the future of the National manufacturing industry, particularly in terms of work-ready Manpower, and (iii) how to generate plans suitable for National action. In attempting to meet these requirements, Indonesia has borrowed heavily from VET policies developed in overseas countries. It has relied, to a significant extent, on the services of visiting experts to create training courses. There has been a varying degree of success attendant to this planning practice (Fairman, 2018). Comment has been made, in this respect, that one of these policy borrowings related to the development and promulgation of the Indonesian Competency Standards, was not based on scholarly research nor evidence-based needs development specifically for the Indonesian context (Cochran \& Malone, 2010).

Lessons learned from this work suggested that several critical questions need to be asked concerning the development of a national planning initiative. They include: (i) how a borrowed policy from abroad could be modified to help inform the specific planning needs of Indonesia and molded into a suitable National policy, (ii) how such revised policy will have the capacity to assess the needs of, and react to, the national economy, (iii) what would be the potential costs, risks and benefits of various approaches, given the wide range of cultures and local needs within Indonesia, (iv) how inherent strains between the development of an academic curriculum and the felt needs of Industry might be manifest, and (v) how, in the practice of VET provision across the country, teaching vs learning philosophies might clash. Clearly, in the Competency Standards example above, potential benefits and the development of relevant policy were not considered (Mitchell \& Young, 2001).

This general lack of critique of policy borrowings from abroad doubtless presages the possibility for further failure for policies when located in an unfamiliar context and where complex issues of practice will inevitably arise. According to Sayuti (2016), the Indonesian Competency Standards policies were developed without a necessary prescriptive set of regulations to guide the implementation process. Guides such as these are especially important when dealing with the complexities of authority and management of VET in Indonesia, where a vast population, geographically spread across a fragmented archipelago and embracing many cultures and specific local needs, makes policy development problematic. This complexity was observed when the National Institute of Public Administration (NIPA) sought to develop a 'policy paper' on technology incubation for Industry, they found that many stakeholders had their own definitions of 'competencies'. Fairman et al (2020) noted, 13 ministries are managing VET institutions, and therefore consistency and determination in managerial approach are critically needed for guiding a national policy initiative (Fairman et al., 2020).

Phan and Siegel (2006) suggest that public policy could forge a basis to catalyze the development for greater engagement between academics, educational providers and industry. There is much to recommend a proactive policy which is attuned to the continually changing conditions of the business and social worlds. The policy must be open to the meeting of changing community service obligations and, at the same time, to be able to work together with industry stakeholders in an increasingly competitive and globalized marketplace. That said, the current Ministry of Education's approach under Kampus Merdeka is to seek engagement with industry not based upon 'community service obligations' but based upon 'incentives and profit'. Kampus Merdeka allows businesses to determine the training requirements in their industry, award certificates of competency to university students undertaking study in their respective companies, additionally students earn university credit for their 'internships' (Yusuf, 2021). Whilst this policy approach is in its formative stages, it remains the expectation of the Minister of Education and Culture, Nadiem Makarin, in detailing the new Merdeka Belajar Kampus Merdeka policy, describes industry competency development as requiring conscientious academic and industry engagement, suggesting that 'Simulating real industry problems, [and] working together with industry professionals is going to be one of the best preparations to combine academic learning in the university with industry'(Neumann, 2021).

\section{National Level Coordination}

A critical function of management is to create a structure through which the agreed National goals can be accomplished. In this regard, Sayuti (2016) perceptively notes that 'Policy standards and objectives need to be clearly stated because performance indicators assess the extent to which standards and objectives are achieved. Lack of clarity around standards and objectives may lead to different interpretations by those charged with their implementation'. A situation of loosely defined policy initiatives and objectives makes national coordination difficult. Consequently, for the implementers of the program, standardization of effort is impossible because of the lack of definition that then requires a projection of these objectives (Van Meter \& Van Horn, 1975). Standards and objectives need a clear explanation and understanding to ensure effective implementation by individuals and organizations.

It must also be noted that the limited number of training modules that were available in the past significantly hindered the adoption and socialisation of the existing policy. Whilst there were 295 modules of the 
Indonesian Competency Standards in a variety of competency areas that were in the process of being developed, only seven per cent of modules had been completed (Abdullah, 2014). In addition, the provision of professional development workshops was limited, which meant that many teachers were left to their own devices in implementing the policy, and coordination of approach became impossible. Many teachers were forced to incorporate the competency standards within the existing curriculum in Vocational Schools, and, as a result, the second core function of the Indonesian Competency Standards policy, that of a curriculum instrument for competency-based education and training, understandably could not occur. Kampus Merdeka policy articulates a shift in the relationship between VET providers and 'industry' in terms of finding ways to provide industry competencies. This policy shift allows Indonesian companies to 'accredit' the necessary competencies required in their respective Industry, companies are responsible for designing the content and learning programs required to be competent in their respective workplaces. The Minister of Education, Republic of Indonesia describes it this way: 'If businesses cannot 'simulate' what is required in their industries, then they should not expect universities to be able to simulate those competencies (Neumann, 2021)'. This paradigm shift in 'competency development' raises questions for the vocational education sector such as; (i) How prepared is VET providers in working with industry? (ii) How prepared are industries to design and measure industry competency standards?

\subsection{Organization of the human, industrial and infrastructural resources}

An essential requirement for management of the VET area is the facilitating of relationships between vocational training institutions and the workforce employing organizations. Such a partnership will provide a critical strategy in ensuring relevant workforce training, familiarity with essential industrial infrastructure, and maintaining a flow of knowledgeable employees in a changing market context. By implication, the onus is upon educational training institutions, especially those involved in training for the workforce, that the industry relationship should be effective and efficient giving personnel a training experience that prepares them for a 'cradle to the grave' relationship with Industry. The rapidly changing global context, including the developments in new technologies with the concurrent growth in infrastructure designed to support the National Industry and services requirements, require a responsive and durable training system to meet these challenges.

Training institutes are the critical interface between employers and employees, their role in establishing and fostering industry partnerships, at the local, regional and national level are central to achieving the human resource development needs across the nation. Managing these partnerships is central to the success; a vital issue here is to ensure that the broadest possible impact of these partnerships is seen through delivery practice and readiness for work outcomes of the students.

For students to gain the necessary competencies in the form of skills, knowledge and attitudes for the world of work the Indonesian policy framework requires a quality assurance platform to ensure compliance across the diverse range of training provision (Yusuf, 2021). As Narayanan (2009) notes, to enhance and establish the engagement between industry and training institutes is to provide course training materials and curriculum that meet the industry training requirements. This engagement will provide a more profound and relevant training experience for the students entering the workforce by simulating the working environment that reflects reality in the workplace. The Indonesian policy framework under Kampus Merdeka includes support for developing programs adopting 'entrepreneurship and innovation' (Purwanti, 2021). Companies involved in delivering Kampus Merdeka run the programs, determine the content and hand out the certificates.

Bridging the cultural and organizational differences between providers and industry remain a challenge. These differences are exacerbated when there were alliances with international business organizations (Hall et al., 2003). This organizational divide, whilst challenging for both industry and VET training institutes, is a necessary precursor for engaging in a global trading environment. To breach this 'divide', some VET institutions have made considerable inroads into heightening engagement with alternative third-parties. Whilst not addressing the issue directly this managed to provide a means of engaging with Industry.

ASEAN member states, particularly Indonesia, are placing considerable effort in linking industrial, technological advances with appropriate training interventions. These innovative programs developed with consideration of business requirements, could be important models for developing and designing vocational education and training interventions into the future. It is noted though, that implementing these reforms is exceptionally challenging, particularly for ASEAN emerging member states who are currently not in a position to access international 'knowhow' promptly.

It is well recognized in management circles that to oversee a complex organization, there is a constant need for ongoing evaluation of progress, appreciating where the strengths and weaknesses lie in the organization and making sure that people in positions are acting appropriately. In the VET area, meeting the challenges of Industry demands in a diverse and disruptive business environment with the concurrent community needs and expectations, VET training staff need to be embracing industry and community training needs. VET managers should remain acutely aware of the impacts of technological change and its effects on the Indonesian economy. An improved policy framework is needed, which will allow the generation of structured collaboration between 
training institutes and employers for meeting industry as well as local economic needs. Implementing a policy framework that enhances the engagement with Industry will necessarily build competence and abilities of the labour force. D'Este and Patel (2007) argue that considerable benefit can be realized in VET outputs when the providers actively engage with industry.

\section{Ensuring the efficacy of partnership management}

Many VET providers are public VET organizations, being established and managed by government ministries. As is typical with most national organizations, there are institutional and bureaucratic issues which need to be addressed. Indonesia, since independence is weighted with bureaucratic requirements, which are often too complex and challenging to navigate. These bureaucratic overlays are just some of the obstacles that VET institutes face to become responsive to industry demands (Perdana et al., 2021). Notwithstanding this somewhat pessimistic view, there must be reasonable controls placed across large organizations to ensure that national objectives are being met. The importance of academic-industry partnerships cannot be overstated, and a 'third hand' being involved in the balance of theory and practice issues is an example of positive control.

The application of external direction, if handled carefully, can help to reduce the perceived barriers caused by excessive bureaucracy. Future success will be framed by Indonesia's willingness to adapt, modify and revise policy interventions and its ability to build more transparent communication and dialogue between ministries and industry to reduce perceived barriers. Notwithstanding these caveats, capacity building personal in training institutes to work with Industry and building and developing training partnerships is integral to achieving success. Industries desire to train their workforce in the face of continual restructuring and upgrading of new technologies, working with at times archaic organizational infrastructure, Industries seek collaboration from training institutes to increase their viability.

Notwithstanding efforts designed to enhance capacity building for VET providers, new concepts and understandings have emerged with the introduction of-globalization, and preparing the future workforce for this added complexity is impacting on industry/provider collaboration. The considerable pressure to internationalize all elements of the workforce introduces new challenges for educational institutions as they attempt to work with Industry.

Globalization impacts are placing new pressures on provider/industry partnerships (Hall et al., 2003). Therefore, partnership diversification is essential in ensuring a broad acceptance and the ongoing relevance of training interventions. Constant communication is vital in not only establishing trust but also in building mutual respect between partners. Doloi (2009) also believes creating partnership environments conducive to productive and honest communication fosters confidence and an enduring basis for collaboration.

\subsection{Implications for practice-VET Institutions}

Whilst VET institutions might be striving to develop their own approach to service delivery suitable for a particular market, there are, nevertheless, factors common to all training partnerships that need to be examined. Effective training providers must recognize several characteristics which have become part of current Indonesian commerce. VET providers need to familiarize themselves with the constant state of flux and competitive market place constraints in order to work synchronistically with businesses. VET providers should actively engage with industry to ensure more relevant interventions, and this is certainly the major thrust of Indonesia's Kampus Merdeka planned interventions. In addition, VET providers need to understand and work with corporate policies and procedures. With such a balanced perspective, educational objectives will be enabled to become more flexible and customized, and training systems will be assisted in growing more streamlined and job-focused.

VET providers, as the preferred training institutions for Industry, are required to manage the expectations of financial and non-financial risk assessments as well as meeting the commercial expectations in the 'real' world. They also are required to have a working comprehension of commercial issues, mainly where speculation and risks are distributed between partners. In addition, they are expected to understand the administrative arrangements necessary for managing partnership programs, to have a sensible overview of program costing, and to have innovative ideas of how course materials might be customized. As a result, legal and contractual arrangements need to be clearly understood.

Social networking is often overlooked in successful industry/training collaborations and partnerships within the VET sector (Abdullah, 2014, p. 258). In this respect, a key responsibility for VET staff is to firmly establish and preserve open and frank communications with local business and Industry. Whereas this responsibility might seem somewhat obvious, a study by Abdullah (Green \& Galetto, 2005) regarding aspects of VET-Industry collaboration found that there was patent lack of communication between the VET managers and their Industry liaison contact.

Another essential management function for VET providers is in the locating and garnering additional financial support, usually through competitive grant submissions, to help develop and sustain new training initiatives. With access to such other funds, VET providers will be equipped to organize an array of human 
capability programs that could meet the demonstrated needs of the various industries located in the region. Abdullah (2014) noted that even though systemic financial aid has been decreasing for higher education and vocational education and training in Indonesia, finance for staff development has improved (Abdullah, 2014).

In order to keep abreast of industry and business development, VET providers are required to promote the need for their training staff to visit and engage with industry sectors as frequently as possible. This engagement is especially pertinent to the management of existing training partnerships, where it is necessary to discuss the industry training requirements. One policy initiative that management could introduce is having more staff undertake 'secondments' to Industry and to seize opportunities for 'on-the-job' training to help them stay connected to their respective industry sectors. VET institutions will be equipped to obtain a range of up-to-date benefits by recognizing and incorporating these policy requirements into their training partnerships with industry. These include developing state-of-the-art curricula to meet current business needs, and utilizing existing training staff, facilities more effectively.

\subsection{Implications for business corporations}

Managers delegated the role of training within their business portfolios might not be fully aware of the organizational performance requirements or even how this is measured in any meaningful way in a relation to working in partnership with an external training provider. Failure to recognize this contribution to business outcomes may affect how a partnership is perceived and therefore, may be a barrier to further projects. It is therefore critical to develop, deliver and evaluate training programs concerning expected levels of improvement in organizational performance. It is seen that such progress will be a fundamental driver of further training initiatives. Consequently, with advised management approaches, a training agenda can be built upon a more sustainable recognition of the financial restraints of the business, whilst acknowledging training as a future investment on human capital productivity. As a result of this, measuring the training providers effectiveness against the partner's expectations particularly in respect of a return on investment affirms the importance of reliable and formally instituted partnerships.

Collaboration for advancing the vocational education standards is important. (Cohen \& Brawer, 2009) emphasize that education is essential for economic expansion. The contribution of educational institutes toward promoting economic development includes acknowledging the importance of a well trained: (i) workforce developed by VET providers, and (ii) administrative staff emerging from development and vocational programs. With this mixture, Industry will be provided with a well-trained team, capable of executing their manufacturing jobs, and being able to realize their future potential in a changing workplace environment Cohen and Brawer (2009). This evaluation of claimed and observed outcomes of training is a key management responsibility. In short, Industry should therefore be cautious in conducting their own assessments of competencies, but should also carefully evaluate the quality of such assessment when their training partner performs them.

\section{Concluding Remarks}

Managing VET provision is an essential part of the successful training agenda. First, there is a continually changing requirement for skills in the multiple workplaces addressed by VET. Second, the external pressures being put on industries due to increasing globalization of services is demanding a refocus of satisfying the traditional market place. Third, the close partnership between VET providers and the industries they serve is accompanied by its own set of management problems/challenges. Frustration with partnerships seems to arise not only from the externally imposed factors (Abdullah (2014) but also from the incompatible bureaucratic structures in partnership institutions (Perdana et al., 2021).

It is sometimes too easy to criticize actions which have been taken with the best of intentions. Nevertheless, in this area of VET provision, it is essential to continually emphasize where Indonesian management structures have been adopted which take into account (i) where cross-cultural issues arise, (ii) where academic vis-à-vis industry strains might become apparent due to differing standpoints and (iii) where teaching vs learning philosophies might clash.

\section{References}

Abdullah, H. (2014). VET Training and Industry Partnerships: a Study in East Java, Indonesia Victoria University].

Cochran, C. L., \& Malone, E. F. (2010). Perspectives and Choices. In: Boulder: Lynne Rienner.

Cohen, A. M., \& Brawer, F. B. (2009). The American community college. Jossey-Bass.

D'Este, P., \& Patel, P. (2007). University-industry linkages in the UK: What are the factors underlying the variety of interactions with industry? Research policy, 36(9), 1295-1313.

Doloi, H. (2009). Relational partnerships: the importance of communication, trust and confidence and joint risk management in achieving project success. Construction Management and Economics, 27(11), 1099-1109.

Fairman, B. (2018). Looking for a way out: Skills development and training and its impact on aid practices and 
their development outcomes, with particular reference to Indonesia and Timor-Leste Victoria University].

Fairman, B., Voak, A., Abdullah, H., \& Indarjo, A. (2020). Re-skilling vocational education and training practitioners in Indonesia. Journal of Physics: Conference Series, 1516, 012045. https://doi.org/10.1088/1742-6596/1516/1/012045

Green, G. P., \& Galetto, V. (2005). Employer participation in workforce development networks. Economic Development Quarterly, 19(3), 225-231.

Hall, B. H., Link, A. N., \& Scott, J. T. (2003). Universities as research partners. Review of Economics and Statistics, 85(2), 485-491.

McLean, J. (2011). Fayol-standing the test of time. Manager: British Journal of Administrative Management, 74 , 32-33.

Mitchell, J., \& Young, S. (2001). High-skilled High-performing VET: A report on change management and staff development strategies required to build the capacity of the VET sector to facilitate the achievement of an integrated, national VET system. Reframing the Future/Australian National Training Authority (ANTA).

Narayanan, T. R. (2009). Academia-industry partnership: an impetus for strengthening teaching and research in higher education institutions. Current Science (00113891), 343-346. https://ezp.lib.unimelb.edu.au/login?url=https://search.ebscohost.com/login.aspx?direct=true \&db=a9h\&AN $=36674033 \&$ scope $=$ site

Neumann, L. (2021, 27/07/2021). The Future of Education in Indonesia In Envisioning Indonesia's Future With Education Minister Nadiem Makarim. https://open.spotify.com/episode/1czRSk2Uphi5dGtlzkNigt?si=VKoKkIPHQhOYDMUaFSQ\&dl branch $=1 \&$ nd $=1$

Perdana, A. B., Indah, S. N., Kusumo, Y. W., \& Ayu, K. (2021). How Does the Diffusion of Kampus Merdeka Innovation Work at the University? International Conference on Engineering, Technology and Social Science (ICONETOS 2020),

Phan, P. H. C., \& Siegel, D. S. (2006). The effectiveness of university technology transfer. Now Publishers Inc.

Purwanti, E. (2021). Preparing the Implementation of Merdeka Belajar-Kampus Merdeka Policy in Higher Education Institutions. 4th International Conference on Sustainable Innovation 2020-Social, Humanity, and Education (ICoSIHESS 2020),

Sayuti, M. (2016). The Indonesian Competency Standards in Technical and Vocational Education and Training: an Evaluation of Policy Implementation in Yogyakarta Province Indonesia The University of Newcastle Australia].

Van Meter, D. S., \& Van Horn, C. E. (1975). The policy implementation process: A conceptual framework. Administration \& Society, 6(4), 445-488.

Yusuf, F. (2021). The Independent Campus Program for Higher Education in Indonesia: The Role of Government Support and the Readiness of Institutions, Lecturers, and Students. Journal of Social Studies Education Research, 12(2), 280-304. 